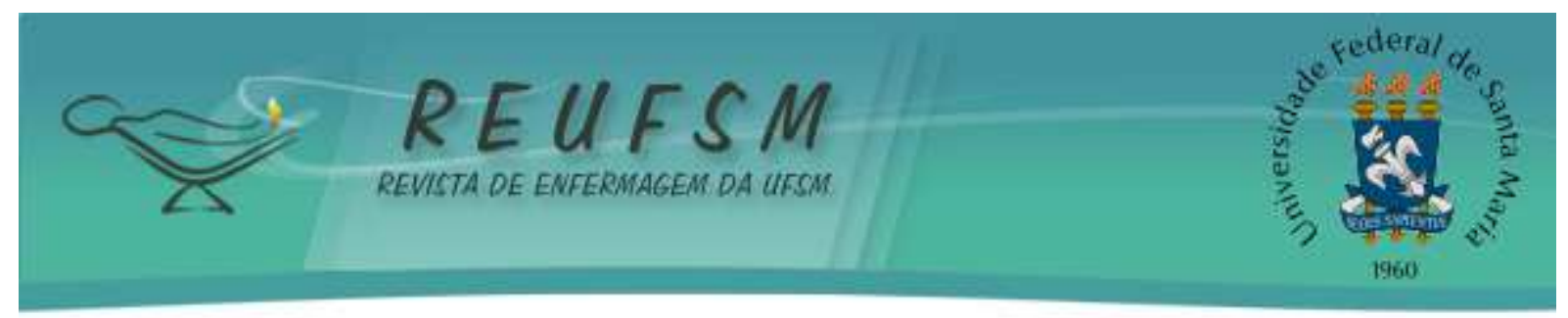

\title{
ACOLHIMENTO: PERCEPÇÃO DE ENFERMEIROS EM UMA UNIDADE DE URGÊNCIA E EMERGÊNCIA
}

\author{
USER EMBRACEMENT: THE NURSES' PERCEPTION IN A URGENCY AND \\ EMERGENCY UNIT
}

\section{ACOGIMIENTO: PERCEPCIÓN DE LOS ENFERMEROS EN UNA UNIDAD DE URGENCIA Y EMERGENCIA}

\author{
Natália Mendes Malta Rodrigues Costa ${ }^{1}$ \\ Rejane Cussi Assunção Lemos ${ }^{2}$ \\ Poliana Silva de Oliveira ${ }^{3}$ \\ Gisele Bento Sgotti ${ }^{4}$
}

Doi: $10.5902 / 2179769229808$

RESUMO: Objetivos: identificar a percepção dos enfermeiros sobre o acolhimento e analisar sua articulação com os fundamentos da Política Nacional de Humanização (PNH). Método: pesquisa qualitativa, com 14 enfermeiros que atuam no Pronto-Socorro Adulto do Hospital das Clínicas da Universidade Federal do Triângulo Mineiro. Os dados foram coletados em dezembro de 2015, por meio de entrevista semiestruturada e analisados conforme análise de conteúdo. Resultados: emergiram as categorias: o acolhimento como atendimento inicial, em que o acolhimento é descrito como ação na entrada do usuário no serviço; acolhimento com vistas à humanização, demonstrando entendimento e aplicação de acordo com a PNH; dificuldades para desenvolver o acolhimento devido à sobrecarga de trabalho, a falta de fluxo e de infraestrutura. Conclusões: os enfermeiros demonstraram compreender o significado de acolhimento. Porém, existem pontos frágeis na aplicabilidade, merecendo atenção dos gerentes de saúde para efetivar que os princípios da PNH sejam garantidos.

Descritores: Acolhimento; Enfermagem; Humanização da Assistência; Serviços médicos de emergência

ABSTRACT: Aim: to identify nurse's perception about the user's adjustment and to analyze its articulation with the fundamentals of the National Humanization Policy (PNH). Method: qualitative research, with 14 nurses working in the Adult Emergency Department of the Hospital das Clinicas of the Federal University of Triângulo Mineiro. Datas were collected in December 2015, through a semi-structured interview and analyzed according to content analysis. Results: the following categories emerged: the user embracement as initial service, where it is described as action on the user's entry into the service; humanization, demonstrating understanding and application according to the $\mathrm{PNH}$; difficulties in developing the user embracement due to overwork, lack of flow and infrastructure. Conclusions: the nurses demonstrated to understand the meaning of the user embracement.

\footnotetext{
${ }^{1}$ Enfermeira. Especialista em Urgência e Emergência. Faculdade Regional de Medicina / FAMERP. São José do Rio Preto, Brasil. E-mail: nataliamaltacosta@gmail.com

${ }^{2}$ Enfermeira. Doutora em Enfermagem. Docente. Universidade Federal do Triângulo Mineiro, instituto de Ciências da Saúde, Curso de Enfermagem. Uberaba, MG, Brasil. E-mail: rcalenf@yahoo.com.br

${ }^{3}$ Enfermeira. Mestre em Ciências pela Escola de Enfermagem de Ribeirão Preto - USP. Enfermeira da Secretaria Municipal de Saúde de Orlândia/SP. Brasil. E-mail: polianasilvaoliveirat@ gmail.com

${ }^{4}$ Enfermeira. Mestranda em Saúde Ambiental e do Trabalhador. Universidade Federal de Uberlândia. Brasil. Email: gi_sgotti@yahoo.com.br
} 


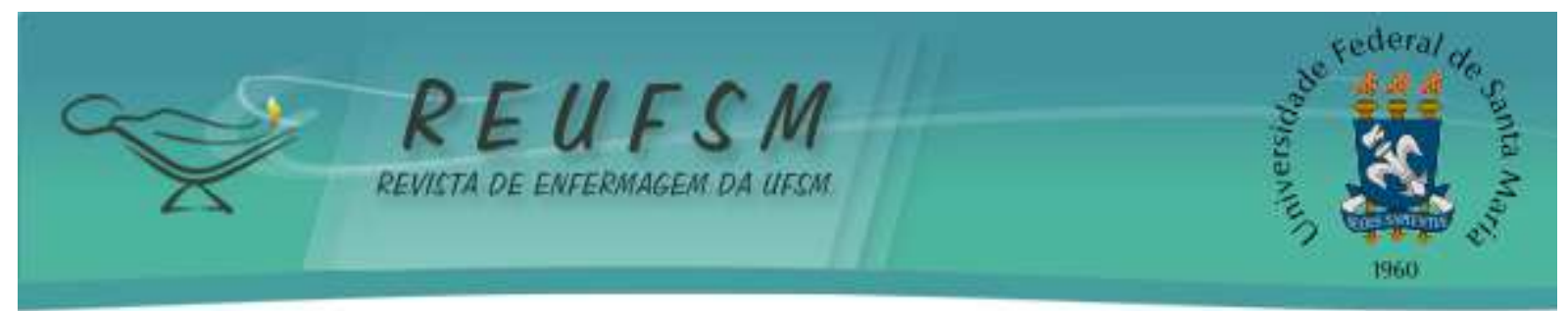

However, there are weak aspects in the applicability, which deserves the attention of health managers to ensure that the principles of PNH are guaranteed.

Descriptors: User embracement; Nursing; Humanization of assistance; Emergency medical services

RESUMEN: Objetivos: identificar la percepción de los enfermeros sobre el acogimiento y analizar su articulación con los fundamentos de la Política Nacional de Humanización (PNH). Método: investigación cualitativa, realizada con 14 enfermeros que actúan en el Puesto de Primeros Auxilios para adultos del Hospital de las Clínicas, de la Universidade Federal do Triângulo Mineiro. Los datos fueron recogidos en diciembre de 2015, por medio de una entrevista semiestructurada y analizados a partir del análisis de contenido. Resultados: fueron identificadas las categorías: acogimiento como atención inicial, en que el acogimiento se caracteriza por la entrada del usuario en el servicio; acogimiento como forma de humanización, demostrando entendimiento y aplicación de acuerdo con la PNH; dificultades para desarrollar el acogimiento debido a la sobrecarga de trabajo, la falta de flujo y de la infraestructura. Conclusiones: los enfermeros demostraron comprender el significado de acogimiento. Sin embargo, hay puntos frágiles en la aplicabilidad que merecen la atención de los administradores de salud para que los principios de la PNH estén garantizados.

Descriptores: Acogimiento; Enfermería; Humanización de la asistencia; Servicios médicos de emergencia

\section{INTRODUÇÃO}

A produção de saúde está intrinsecamente ligada à organização do processo de trabalho, podendo ser reconhecida no encontro entre o trabalhador de saúde e o paciente. Neste contexto, é necessário um (re) olhar sobre as práticas profissionais, no qual trabalhadores lançam mão de dispositivos para organizarem seu processo laboral e produzirem as ações de saúde. Estes dispositivos podem ser classificados como: tecnologias leves, leve-duras e duras. ${ }^{1}$

As tecnologias leves estão ligadas ao campo das relações como, por exemplo, o vínculo, a escuta qualificada e o acolhimento. ${ }^{1}$ Neste estudo, destaca-se especialmente o acolhimento que, segundo a Política Nacional de Humanização (PNH), é o ato de reconhecimento da legitimidade e da singularidade das necessidades de saúde do outro. $\mathrm{O}$ acolhimento é descrito como estratégia que visa garantir acesso, ampliar a efetividade das práticas de saúde, assegurando que todos possam ser escutados de maneira qualificada, valorizando as demandas trazidas por cada usuário, o que permite avaliá-los e cuidá-los. ${ }^{1-2}$

A PNH apresenta o acolhimento como uma de suas principais diretrizes, exercendo um esforço incessante por uma postura consciente e qualificada dos profissionais de saúde, visando à efetividade da assistência. Além disso, busca a alteração do modelo biomédico, que 


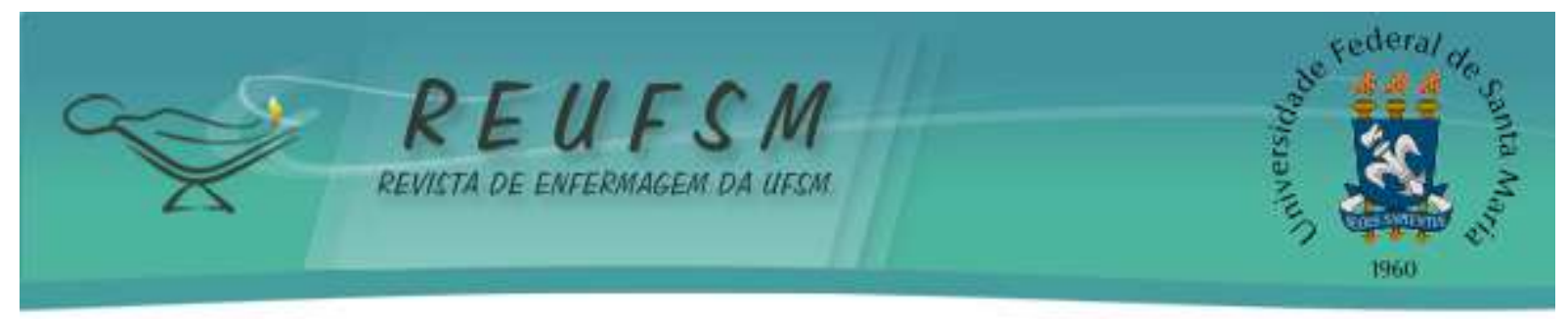

é centrado na doença, no biológico e no saber do profissional médico, para um modelo de fato amplo, multiprofissional, biopsicossocial e participativo. ${ }^{2}$

O acolhimento é uma tecnologia potente para uma condução harmoniosa, estética, significativa e abrangente dos modos de se produzir saúde, pois permite a integração e qualificação de outras tecnologias como a escuta, o vínculo, o acesso, a responsabilização e a resolutividade das necessidades de saúde da população. ${ }^{3}$ Outra peculiaridade do acolhimento é a sua faculdade de transversalidade, permeando todos os níveis de atenção e modos de assistir nos variados núcleos profissionais. Diante de tantas particularidades, confirma-se o acolhimento como diretriz e dispositivo, não podendo ser confundido como um ato de benevolência, mas sim como uma ferramenta para prática do cuidado à saúde. ${ }^{2,4}$

Verifica-se nos serviços de Urgência e Emergência (UE) que mudanças significativas foram realizadas para melhoria da qualidade do cuidado, tais como a criação do Serviço de Atendimento Móvel de Urgência e Emergência (SAMU) e as Unidades de Pronto Atendimento. Estas são alterações estruturais e organizacionais importantes. No entanto, é indispensável investir cada vez mais no campo das relações interpessoais e no fortalecimento dos recursos humanos. Dessa forma, acredita-se que o acolhimento promove a (re) significação de atitudes e olhares. ${ }^{3}$

O pronto socorro (PS) é uma unidade destinada ao atendimento a pacientes em estado de urgência e emergência. Esse setor, fundamental para o Sistema Único de Saúde (SUS), usualmente é composto por uma equipe multiprofissional, sendo que o enfermeiro possui importante papel gerencial e assistencial. Um ponto relevante em suas atividades é a promoção do cuidado holístico, pautado nos preceitos da humanização, incorporando o acolhimento como uma vertente a ser trabalhada. ${ }^{5-6}$

A equipe de enfermagem tem atuado de maneira relevante no acolhimento prestado no PS. Uma das práticas que compõem o acolhimento é a classificação de risco, sendo o enfermeiro responsável pela sua realização. Essa ferramenta possibilita um atendimento sistematizado e proporciona uma avaliação das condições clínicas do paciente, priorizando-se a urgência de acordo com a sua gravidade, não se preocupando apenas com a ordem de chegada do paciente ao serviço. ${ }^{6-7}$ Em estudo realizado na atenção primária, foi identificado que o acolhimento era centrado na doença, não abordando o paciente de forma integral, 


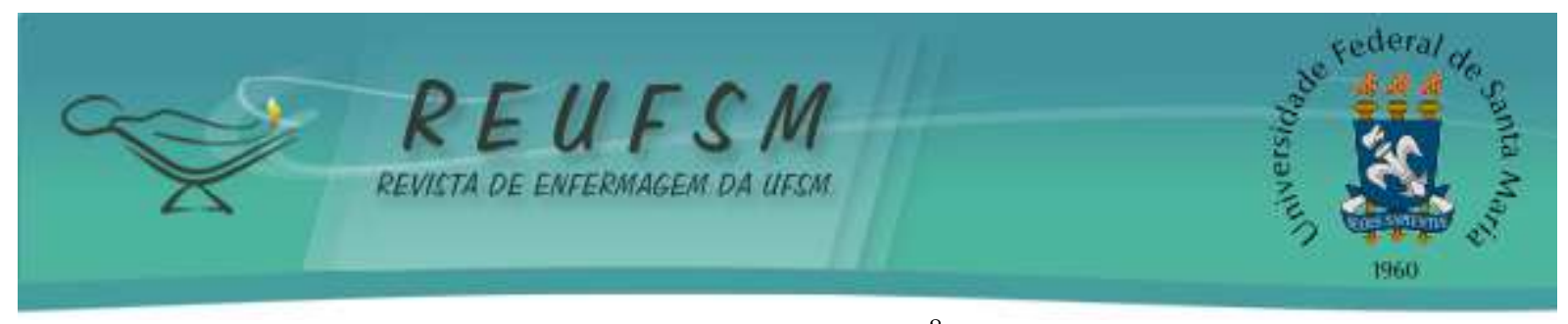

culminando no desmembramento das ações em saúde. ${ }^{8}$ Outras pesquisas apontam que estas evidências também têm sido observadas nos serviços de urgência e emergência. ${ }^{6-7}$

Diante do exposto, o acolhimento pode ser entendido como elemento inerente ao processo de trabalho desenvolvido pelos profissionais de saúde nos serviços de urgência e emergência. Desta forma, apresenta-se como questão norteadora: Qual a percepção que os enfermeiros do Pronto-Socorro Adulto do Hospital das Clínicas da Universidade Federal do Triângulo Mineiro (PSA-HC-UFTM) apresentam sobre o acolhimento? Partindo da necessidade de realizar o acolhimento como dispositivo de assistência, este estudo teve como objetivo identificar a percepção dos enfermeiros sobre o acolhimento e analisar sua articulação com os fundamentos da Política Nacional de Humanização (PNH).

\section{MÉTODO}

Trata-se de um estudo qualitativo por auxiliar a interpretação de respostas individuais, podendo utilizar o subjetivismo como valores, significados e atitudes, para maior entendimento das particularidades e atitudes do ser. ${ }^{9}$ Assim sendo, possibilita identificar a percepção dos enfermeiros sobre o acolhimento e analisar sua articulação com os fundamentos da Política Nacional de Humanização (PNH).

A pesquisa foi realizada no Pronto Socorro Adulto do Hospital de Clínicas da Universidade Federal do Triângulo Mineiro (PSA-HC-UFTM), instituição de saúde de referência para atendimento de urgência e emergência na cidade de Uberaba e região. Realizou-se no mês de dezembro de 2015, tendo como população de estudo 20 enfermeiros que atuavam na referida unidade.

A priori, a amostra não foi definida, uma vez que foi utilizada a técnica de saturação de dados. Esta técnica auxilia o pesquisador a definir sua população, analisando se as informações fornecidas estão favorecendo a pesquisa com novos dados. ${ }^{9}$

Realizou-se entrevista semiestruturada, com 14 enfermeiros dos diferentes turnos de trabalho da unidade (manhã, tarde e noite) do total de 20 enfermeiros que trabalham no PS estudado. Os critérios de inclusão estabelecidos foram: atuar como enfermeiro; trabalhar no setor há mais de um mês (tempo necessário à adaptação desse profissional às rotinas do setor); sendo excluídos os participantes que estivessem gozando de férias ou licenças no período da coleta de dados. 


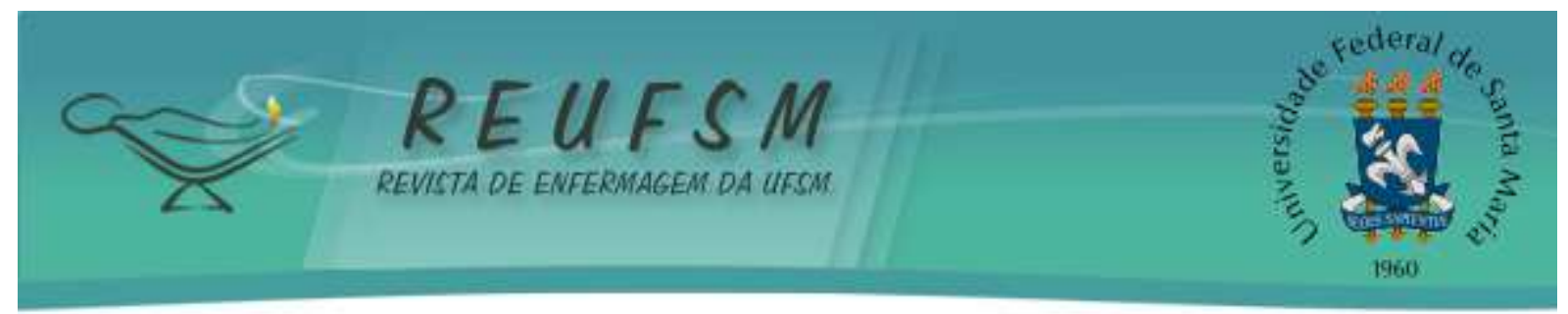

A entrevista foi aplicada tendo a seguinte questão norteadora: Qual a percepção que os enfermeiros do PSA-HC-UFTM apresentam sobre o Acolhimento? Além disso, os participantes foram caracterizados conforme o sexo, estado civil, tempo de formação e tempo de trabalho no setor.

O projeto foi submetido ao Comitê de Ética em Pesquisa e aprovado sob protocolo $\mathrm{n}^{\circ}$ 46188915.1.0000.5154. A coleta de dados teve início após aquiescência do comitê e a participação dos enfermeiros somente foi efetivada após leitura e assinatura do Termo de Consentimento Livre e Esclarecido. As entrevistas foram realizadas no próprio local de trabalho, em lugar reservado, com tempo de duração de 5 a 25 minutos, sem ônus para o participante, sendo informado e concedido a gravação da entrevista por meio de um gravador. Portanto, todos os aspectos éticos previstos na resolução 466/2012 foram contemplados.

Após a coleta de dados, as entrevistas foram imediatamente transcritas na íntegra pelo pesquisador e analisadas segundo referencial teórico de Análise de Conteúdo, que propõe uma metodologia pautada na análise das falas dos participantes, tendo por objetivo compreender os significados. Esta técnica abrange as seguintes etapas: pré-análise; exploração do material e tratamento dos resultados; inferência; e interpretação, as quais foram seguidas. ${ }^{10}$

Para se preservar o anonimato dos participantes, foram utilizados códigos que representam as falas das entrevistas transcritas. Após analisar e categorizar as entrevistas, agrupou-se as falas que continham o mesmo significado. Ao final, surgiram as categorias da pesquisa.

\section{RESULTADOS E DISCUSSÃO}

Foram entrevistados 14 enfermeiros, sendo que $85,71 \%$ eram do sexo feminino e 14,29\% ao sexo masculino, com média de idade de 33 anos. Quanto ao estado civil, 57,14\% eram solteiros; $35,71 \%$ casados e 7,14\% divorciados. Observou-se que a média de tempo de formação foi de sete anos e o tempo de trabalho no setor variou de seis meses a quatro anos. Da amostra, 11 enfermeiros relataram ter realizado o curso de capacitação para acolhimento com classificação de risco, enquanto três enfermeiros não o realizaram.

As categorias que emergiram da análise dos dados foram: acolhimento como atendimento inicial, acolhimento com vistas à humanização e dificuldade para desenvolver o acolhimento, as quais são discutidos. 


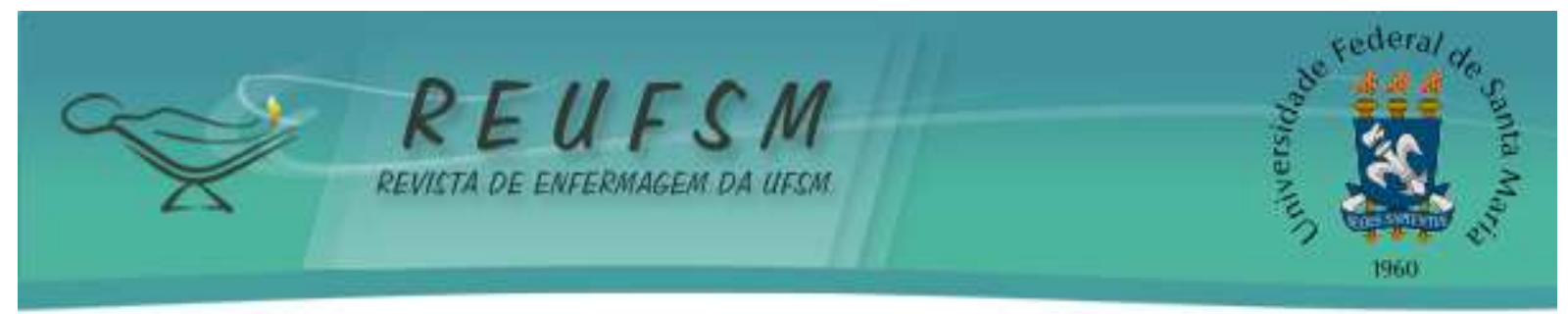

\section{Acolhimento como atendimento inicial}

Em relação ao significado do acolhimento na percepção dos enfermeiros, esse foi compreendido como o atendimento de porta de entrada aos pacientes que chegam ao PSA, uma triagem, na qual o paciente é recebido/recepcionado pelo enfermeiro, momento em que se realiza uma avaliação inicial. Escutar a história ou a queixa do paciente é apontado como relevante. Esta percepção pode ser identificada diante das seguintes falas:

[...] é a forma de você receber o paciente que chega na instituição. Uma maneira de você ouvir as queixas dele, o que ele tem pra te falar e também a forma de quantificar os riscos, fazer a classificação de risco e ver o grau de complexidade do quadro do paciente. (ENT 03)

Acolher é você ouvir o outro, é estar disposto a ajudar, estar disposto a proporcionar um direcionamento com aquela demanda que o paciente chega pra você [...] dar o primeiro atendimento, conversar e atender as suas demandas e estar direcionando ele para um atendimento mais adequado. (ENT 14)

[...] o acolhimento é a porta de entrada do hospital [...] todos os pacientes que chegam têm que dar um direcionamento. Tem aqueles que são porta aberta que a gente vai ouvir a história e vai dar um encaminhamento, e tem aqueles que a gente tem que encaminha para outros serviços de nível secundário [...] Tem que encaminhar para um serviço pra ela não fica sem atendimento. (ENT 13)

Alguns profissionais interpretam o acolhimento como uma ação pontual inicial. No entanto, realizar o acolhimento não é apenas ouvir o motivo pelo qual o paciente procurou o serviço, é promover a escuta qualificada, identificar as suas necessidades, ultrapassando as queixas biológicas. Dessa maneira, o profissional desenvolve uma postura de corresponsabilização. ${ }^{4}$ Nesse contexto, é fundamental que a lógica do acolhimento esteja ligada a assistência prestada, não se resumindo apenas à entrada do paciente ao serviço. ${ }^{11}$

Alguns estudos ${ }^{11-12}$ demonstram que compreender o acolhimento e sua relação com a prática profissional possibilita o questionamento da postura dos profissionais e dos serviços na efetivação das diretrizes propostas pelo SUS, em busca de uma assistência humanizada e de qualidade.

A Classificação de Risco foi outra concepção identificada nas entrevistas. Essa é uma ferramenta que auxilia a prática do acolhimento, atendendo o paciente conforme a sua gravidade e não por ordem de chegada, abrangendo todo o processo de cuidado que deve ser ofertado. ${ }^{4}$ A classificação de risco está contida no acolhimento, devendo ser utilizada após a 


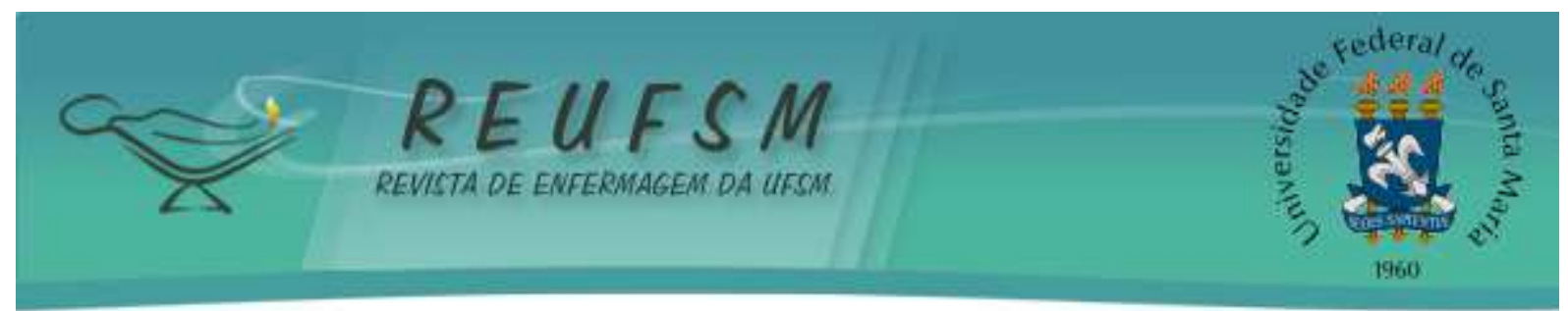

avaliação do profissional sobre o problema que trouxe o paciente até a unidade. Contudo, ao analisar as falas dos participantes, percebe-se que os profissionais expressam que o ato da classificação de risco é o mesmo que realizar uma triagem, sendo também considerado o ato em si do acolhimento, como demonstrado nas falas a seguir:

[...] precisa ter alguém aqui que direcione quem vem, quem não vem. Quem tem condições de ser atendido em uma UPA (Unidade de Pronto Atendimento) [...] priorizar o atendimento aqui que geralmente é emergência [...] fundamental para fazer essa triagem, esse filtro, definir/otimizar os leitos na verdade. (ENT 12)

Todos os pacientes que chegassem tinham que ser [acolhidos], teria que ter um impresso próprio para você registrar todos os atendimentos que vocêfez, aferir todos os sinais vitais e com isso, ter um embasamento melhor pra você triar esse paciente, para sabe qual classificação de risco que ele vai se enquadrar e nós não temos isso. (ENT 07)

O acolhimento não se limita apenas à triagem dos pacientes, transpassa essa ótica, por vezes, desenvolvida pelos profissionais. A definição de acolhimento não deve ser pautada em ações realizadas separadamente, tendo em vista que essa conduta pode levar à segregação do cuidado, restringindo apenas à 'triagem". ${ }^{13-14}$

O Acolhimento com Classificação de Risco (ACR) integra a PNH como dispositivo tecnológico para auxiliar o profissional a lidar com as demandas das urgências e emergências do serviço, propondo outro modelo de atendimento, fundamentado nas necessidades e gravidade dos pacientes e não por sua ordem de chegada ao serviço. Priorizar os pacientes com maior risco, ouvir os familiares sanando suas dúvidas e esclarecendo sobre a gravidade do quadro de saúde do paciente, melhorar o acesso e seu tempo de espera para o atendimento são propostas da ACR. ${ }^{4}$ Ao realizar o ACR, é necessário que os profissionais reflitam sobre as questões que envolvem a integralidade do cuidado proposta pelo SUS, pois estar atento apenas aos sinais e sintomas do paciente não garante acesso de qualidade e integral. Os dados demonstram que os trabalhadores ainda não conseguem diferenciar o ACR da prática da triagem, tratando ambos como sinônimos.

A compreensão do acolhimento como atendimento inicial remete à recepção do paciente no pronto-socorro, onde os sinais e sintomas são expostos, observados e captados pelo profissional de saúde. Neste sentido, a classificação de risco é instaurada como definidora na prioridade do atendimento, sendo característica essencial no atendimento. 


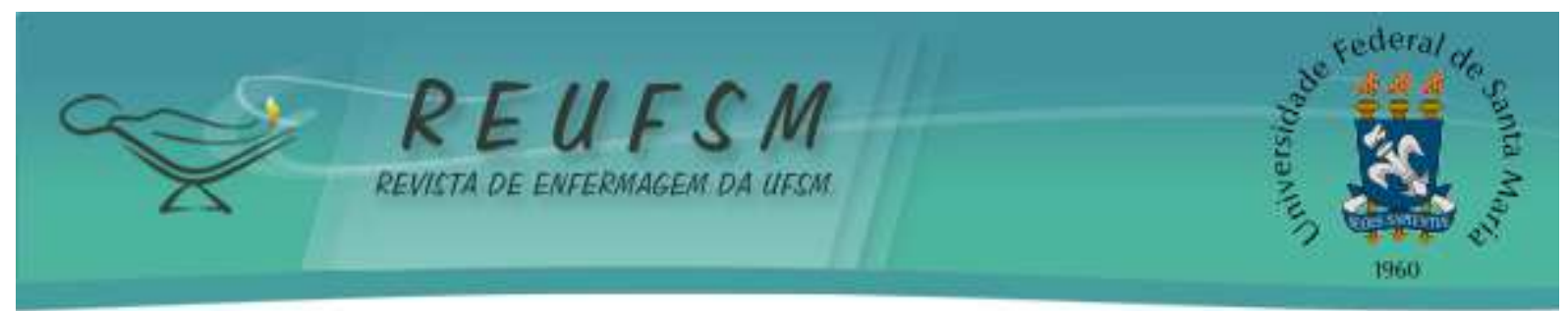

Porém, a escuta ativa e o atendimento holístico são primordiais para que o cuidado ofertado seja de qualidade. A assistência só será completa quando o paciente for tratado integralmente, levando em consideração todas as suas necessidades.

\section{Acolhimento com vistas à humanização}

As práticas de saúde voltadas para o modelo biomédico que priorizam a doença não são suficientes para se obter uma atenção mais integral aos pacientes que procuram os serviços, pois elas não visualizam o paciente de uma forma global e holística. Portanto, reestruturar os serviços de saúde é uma necessidade à efetivação da PNH, que deve englobar trabalhadores, usuários e coordenadores das unidades. ${ }^{2-11-14}$

Apresenta-se, nesta categoria, a compreensão dos profissionais entrevistados sobre os aspectos que ligam o acolhimento a humanização da assistência:

[...] é uma forma de você visualizar o paciente como um todo, você acolher ele não é só chegar, olhar os sinais vitais, não! É você também entender que ele está chegando de casa ou da rua e está com dor, entrando na instituição, que ele deve está assustado, preocupado, ansioso, com medo, eu acho que inclui toda essas características [...]. (ENT 04)

O acolhimento avalia a demanda do paciente, a fim de atender às suas necessidades, tanto no sentido clínico, quanto no sentido social e psicológico. (ENT 10)

Os resultados encontrados corroboram com a literatura quando evidenciam a particularidade que cada paciente possui e que conduz as ações para desenvolver o atendimento em saúde. ${ }^{15}$ Com isso, os profissionais compreendem a necessidade de realizar a assistência voltada para aspectos que envolvam a humanização, pautando suas atividades conforme a demanda de cada paciente e não padronizando seu método de trabalho para todos que procuram um serviço de saúde.

O entendimento holístico ao paciente necessita mais do que condições ideais de trabalho. $\mathrm{O}$ aspecto humano que envolve essa questão, requer profissionais, gestores e unidade de saúde que paute, suas práticas na política de humanização. ${ }^{16-18}$ Os relatos dos entrevistados demonstram o quanto a humanização se faz necessária ao cuidado.

Às vezes você recebe ele de forma muito rápida, de uma forma muito burocrática e acaba ficando mesmo. Ele acaba virando um número a mais no corredor, na sala de emergência inicialmente, para depois 


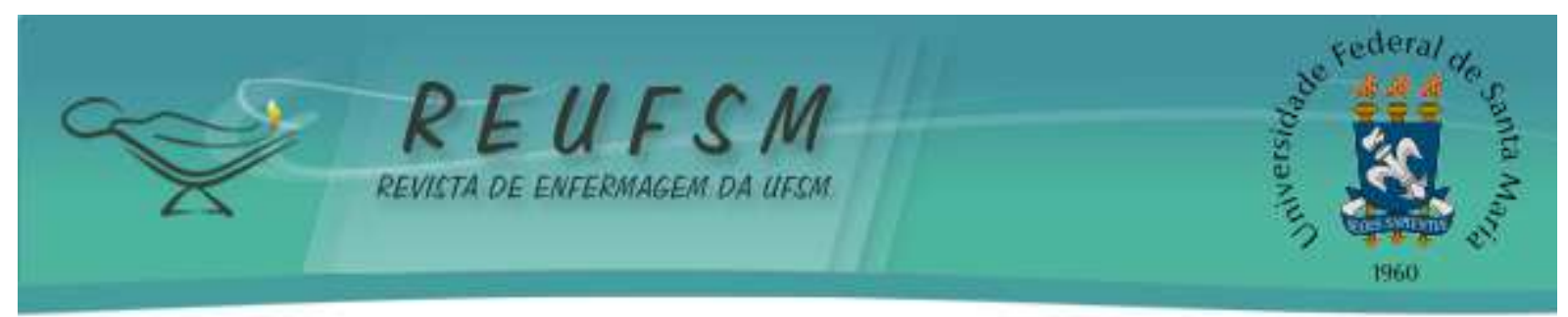

você conseguir conversa um pouco com ele, falar sobre o problema dele. Praticar um pouco dessa resolutividade acaba demorando um pouco e acaba não sendo no momento do acolhimento [...] eles fazem essa admissão inicial do paciente e passam para gente, mas acho que tinha que ser mais, mais tempo com o acolhimento nessa questão mesmo de conversa com o paciente, colher todos os dados, saber dos anseios [...].(ENT 01)

A fala demonstra aspectos negativos em relação aos profissionais como a recepção inadequada, de forma rápida, não escutando os anseios dos pacientes, produzindo um processo de saúde, no qual o singular não tem vez. Essa questão é inaceitável frente aos preceitos da $\mathrm{PNH}$, nos quais as práticas de saúde devem estar voltadas ao paciente, garantindo assistência adequada e de qualidade. ${ }^{2}$ Ao realizar ações que humanizam o cuidado, o profissional efetiva o seu trabalho, garantindo um atendimento adequado, preservando os direitos de saúde do paciente, atendendo a suas necessidades e não simplesmente agindo de modo gentil, mas efetivando o seu trabalho com compromisso. ${ }^{17-18}$ Logo, entende-se que o acolhimento não deve ser visto como mais um serviço a ser realizado pelo profissional, mas incorporada ao processo de trabalho de forma a auxiliá-lo.

\section{Dificuldades para desenvolver o acolhimento}

A falta de funcionários, sobrecarga de trabalho e falta de um fluxo de atendimento são alguns dos pontos que os entrevistados indicam como barreiras que prejudicam a aplicabilidade do acolhimento.

[...] assim, eu acho que a gente poderia fazer mais, mas [...] pela sobrecarga a gente não tem como fazer tudo que a gente poderia estar fazendo pelo paciente [...] mas a gente tenta fazer o possível. (ENT 02)

[...] precisa ter os protocolos de referência e contrarreferência, precisa ter o regimento interno do acolhimento, como funcionam os fluxos, tudo direcionado para que a gente possa atender cada particularidade [...], porque não tem esse fluxo. [...] falta organizar o serviço na rede [...]. (ENT 05)

[...] com os treinamentos, com uniformização, confecção de fluxos, protocolos, para estar seguindo uma mesma linha em todos os períodos, horários, dias da semana, que o serviço funcione independente de quem esteja [...] está melhorando a entrada, a recepção, escuta das pessoas, uma escuta mais qualificada para está direcionando os usuários para não ficar ninguém desamparado. (ENT 14) 


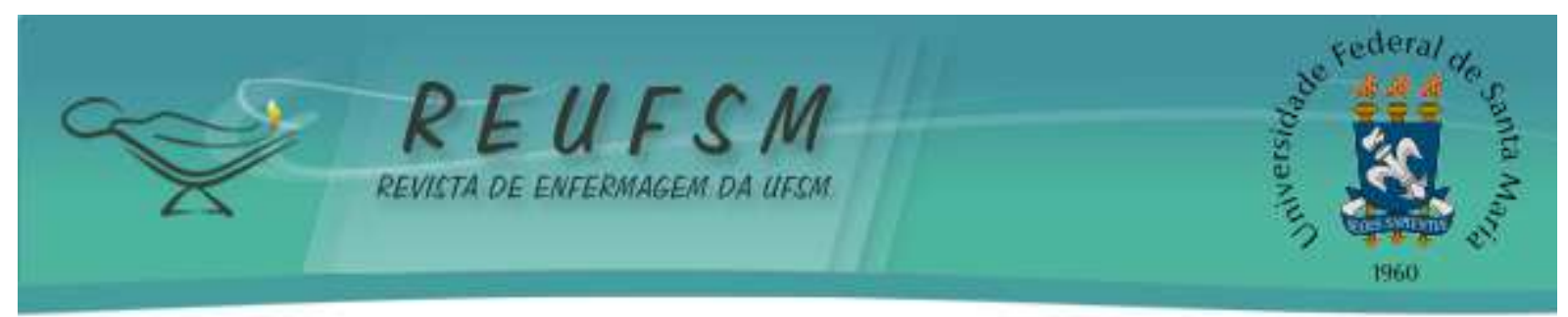

[...] ter um funcionário exclusivo para lá [acolhimento], porque na forma que está sendo feito hoje a gente está fazendo um rodizio. Ou todos os profissionais são preparados para passar pelo acolhimento inclusive com o protocolo de Manchester [...] tem que ser usado da maneira como se deve [...] hoje em dia não é possível ser feito [...] a gente não tem quantidade mínima de funcionário, está com uma demanda muito grande de paciente [...]. (ENT 13)

Outras pesquisas também apontam a 'superlotação' e a 'sobrecarga' de trabalho como fatores que dificultam a realização do acolhimento nos serviços de saúde. ${ }^{19-21}$ Por conseguinte, assegurar a melhoria no atendimento do paciente não está desvinculada da busca por condições adequadas de trabalho, incluindo a contratação de profissionais capacitados, em quantidade suficiente para oferecer uma apropriada assistência.

A adesão a protocolos pode auxiliar no direcionamento do paciente, assegurando ao profissional a correta conduta a ser estabelecida. ${ }^{11,16,22}$ Para os participantes da pesquisa, a redefinição dos fluxos de atendimento da unidade facilitaria as atividades de enfermagem. Além disso, estabelecer um fluxo adequado também contempla compreender os níveis de atenção que o SUS propõe. Um estudo na Suécia identificou que muitos casos atendidos em um serviço de emergência poderiam ser realizados em outros níveis de atenção de menor complexidade, o que diminuiria o alto fluxo de atendimento com consequente melhora na qualidade do atendimento prestado, o que beneficiaria o sistema de saúde e os pacientes. ${ }^{23}$ Uma melhor compreensão dos profissionais e pacientes quanto aos níveis de atenção poderia auxiliar no entendimento do fluxo, refletindo em melhorias na organização dos serviços de saúde e atendimento ao pacientes.

Estudos $^{24-25}$ tratam sobre a satisfação dos pacientes nos serviços de urgência e emergência e mostram que grande parte dos pacientes não conhecem o sistema de classificação de risco, o que acarreta insatisfação por parte dos mesmos. Nesse sentido, aponta-se a necessidade da inclusão dos pacientes na definição, organização dos fluxos de atendimento e do cuidado prestado. É certo que o entendimento por parte da população de uma melhor maneira de funcionamento do sistema possibilitaria atendimentos mais dinâmicos e de qualidade, o que é primordial nos serviços de urgência e emergência.

Outro aspecto que emergiu nos dados se relaciona à estrutura física. Apresentado também em outros estudos, a falta de recursos físicos e materiais é obstáculo para a prática do acolhimento. $^{12-19}$ 


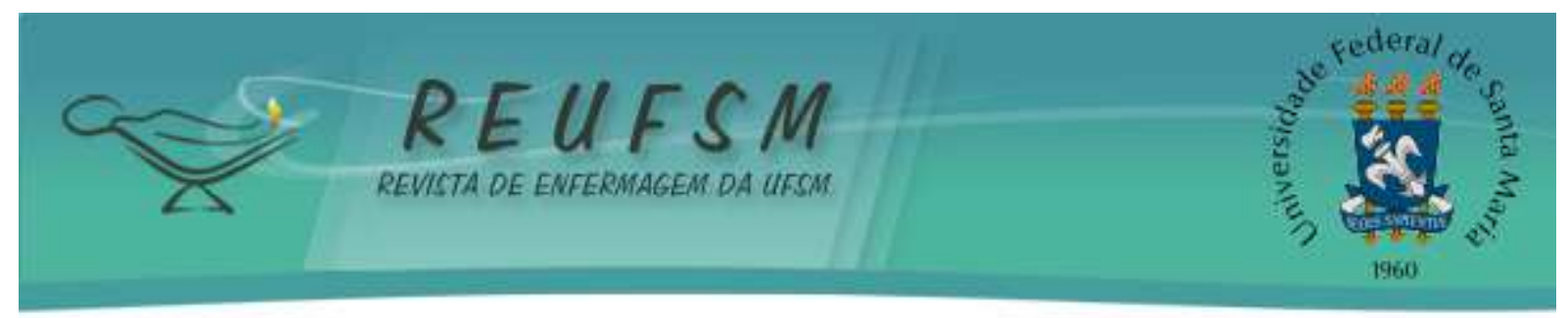

É um serviço que precisaria de uma estruturação, por exemplo, às vezes falta maca e o paciente fica lá fora a manhã toda. Ás vezes, consegue colocar o paciente as cinco horas da tarde. (ENT 04)

Eu acho que o acolhimento é realizado de modo ineficaz, porque tem coisas que são dificultadoras, por exemplo, falta de maca, às vezes tem um paciente que ele chega ele é acolhido. A enfermeira do acolhimento vê que é um paciente que realmente tem que ficar aqui internado, mas às vezes ele fica o dia inteiro esperando por uma maca, então foi feito o acolhimento da maneira correta, eficaz, porém a falta de maca impediu que esse paciente fosse internado [...] (ENT 03)

Aponta-se, desta forma, o papel da gestão dos serviços de saúde na prática do acolhimento e na atenção à saúde de qualidade. A própria PNH apresenta a característica da indissociabilidade entre a gestão e a assistência, e a transversalidade da política de humanização a saúde. $\mathrm{O}$ ato do acolhimento está diretamente ligado às ações desempenhadas pelos gestores dos diversos serviços de saúde, inclusive na atenção às urgências e emergências. ${ }^{2,4}$

É importante o apontamento realizado pelos profissionais ao citarem como dificultador do acolhimento as estruturas físicas inadequadas, percebendo-se um olhar mais ampliado ao processo de trabalho e assistência. Neste sentido, o acolhimento ultrapassa o sentido de atendimento inicial, abrangendo também o caminhar do paciente dentro do serviço.

Considera-se que as dificuldades para desenvolver o acolhimento transcendem as características individuais dos profissionais de saúde. Verifica-se, com as falas dos enfermeiros, que as demandas de pacientes não estão sendo direcionadas de maneira organizada, levando ao acúmulo e a falta de qualidade nos atendimentos em setores como os de urgência e emergência.

\section{CONSIDERAÇÕES FINAIS}

$\mathrm{O}$ acolhimento é uma diretriz proposta pela PNH que tem como objetivo a melhoria na atenção oferecida aos pacientes nos diversos serviços de saúde. No presente estudo analisou-se o conceito de acolhimento, a partir da percepção dos enfermeiros do PSA e de sua articulação com a PNH. Identificou-se que o ato do acolhimento ainda está relacionado ao atendimento inicial e triagem dos pacientes que chegam ao PSA. No entanto, também foi possível perceber o entendimento ligado ao encontro do paciente e do profissional com respeito a singularidade de cada caso, o que evidência um movimento de incorporação da concepção do acolhimento de acordo com a PNH, transpondo a visão cultural do acolhimento como benevolência e gentileza. 


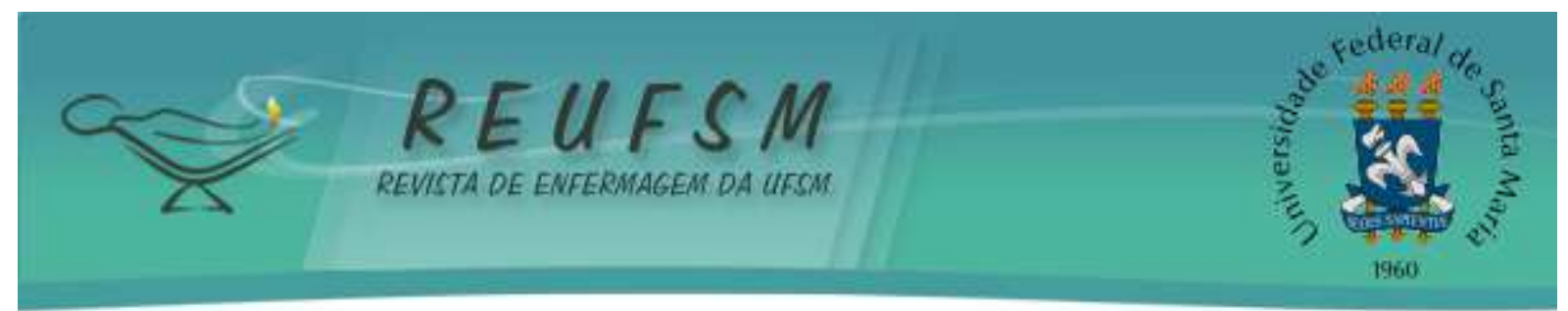

Outro ponto apresentado foram os obstáculos que impedem a prática efetiva do acolhimento, com destaque para a superlotação, muitas vezes, ligada a falta de fluxos estabelecidos sobre o atendimento dos pacientes em outros serviços, como os da atenção primária por exemplo. Falhas nas vias de referência e contra referência dificultam o fluxo correto de pacientes, sobrecarregando o setor de pronto atendimento. Associada a esta questão, a estrutura inadequada somada à falta de recursos materiais e humanos, também promovem a falta de efetivação do acolhimento no serviço.

Sabe-se que o acolhimento é base fundamental para a instauração e reestruturação da assistência no setor de PSA e que para sua concretização, é necessário o envolvimento entre paciente, profissionais e gestores de saúde. Os gestores devem promover condições para a efetivação do cuidado em saúde, permitindo que as equipes de saúde de fato estejam completas, com a quantidade suficiente de profissionais, estrutura física adequada. É função tanto dos trabalhadores, quanto dos pacientes, terem uma participação efetiva nas instâncias formais de controle social e no cotidiano dos serviços de atenção à saúde.

Tendo em vista que a equipe do PSA é composta por várias classes profissionais, pelos gestores e pelos pacientes, os limitantes da pesquisa estão relacionados ao conhecimento de apenas uma parte dela, os enfermeiros. Outro limite do estudo é o fato de que se identificou a percepção do acolhimento o que não permite a avaliação de como em ato ele é realizado. Estudos que contemplem metodologias que possibilitem a apreensão e prática do ato em si do acolhimento, que incluam outros sujeitos dessa prática como outras categorias profissionais e que também observem os entendimentos de pacientes e gestores, apresentam o potencial de auxiliarem no avanço da implantação/implementação do acolhimento como dispositivo nas práticas de atenção à saúde.

A pesquisa científica relacionada à percepção dos enfermeiros quanto ao acolhimento constitui importante estudo frente à busca de melhorias na qualidade da assistência. É importante que o enfermeiro como membro da equipe de saúde e gestor da equipe de enfermagem tenha um conhecimento científico e articulado com as políticas de saúde vigentes. Conhecer os possíveis conceitos que perpassam a realização do acolhimento por enfermeiros de serviços de urgência e emergência permite identificar a necessidade e a organização de processos de educação permanente em saúde para uma aprendizagem significativa, com vistas a mudanças nos processos de trabalho e melhorias no cuidado 


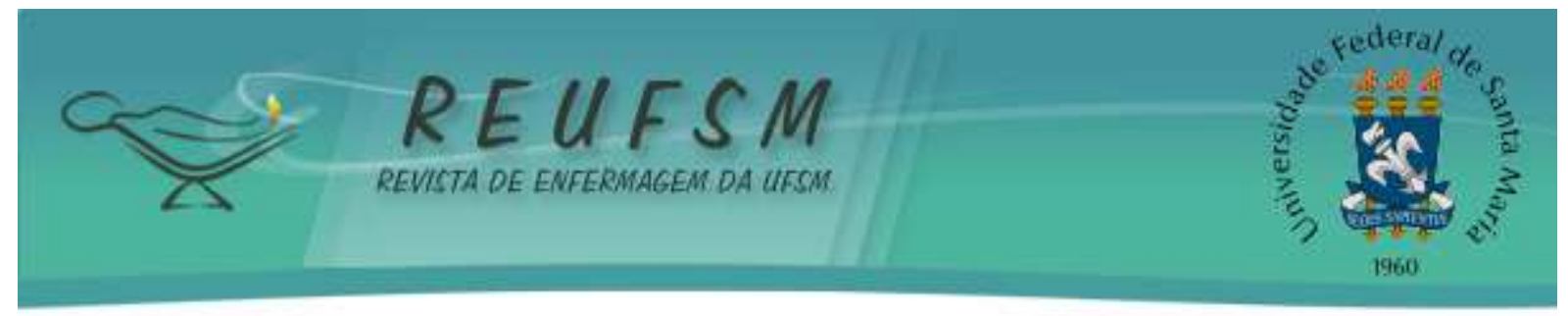

prestado. A partir do conhecimento aprofundado e científico é que se possibilita o aperfeiçoamento de condutas e de teorias.

\section{REFERÊNCIAS}

1. Merhy EE. Saúde: Cartografias do trabalho vivo. São Paulo: Hucitec; 2002.

2. Brasil. Ministério da Saúde. Humaniza SUS: Política Nacional de Humanização: PNH. Brasília: Ministério da Saúde; 2013 [acesso em 2017 jan 20]. Disponível em: http://bvsms.saude.gov.br/bvs/publicacoes/politica_nacional_humanizacao_pnh_folheto.pdf.

3. Brasil. Ministério da Saúde. Secretaria de Atenção à Saúde. Núcleo Técnico da Política Nacional de Humanização. Acolhimento nas práticas de produção de saúde. Brasília: Editora do Ministério da Saúde; 2010.

4. Brasil. Ministério da Saúde. Secretaria de Atenção à Saúde. Política Nacional de Humanização da Atenção e Gestão do SUS. Acolhimento e classificação de risco nos serviços de urgência. Brasília: Ministério da Saúde; 2009.

5. Almeida Q, Fófano GA. Tecnologias leves aplicadas ao cuidado de enfermagem na unidade de terapia intensiva: uma revisão de literatura. HU Revista, Juiz de Fora [Internet]. 2016 setout [acesso em 2017 jan 25];42(3):191-6. Disponível em: https://hurevista.ufjf.emnuvens.com.br/hurevista/article/view/2494.

6. Lima Neto AV, Nunes VMA, Fernandes RL, Barbosa, IML, Carvalho GRP. Acolhimento e humanização da assistência em pronto-socorro adulto: percepções de enfermeiros. REUFSM [Internet]. 2013 [acesso 2017 fev 20];3(2):276-86. Disponível em https://periodicos.ufsm.br/reufsm/article/view/8279.

7. Duro CLM, Lima MADS, Weber LAF. Opinião de enfermeiros sobre classificação de risco em serviços de urgência. REME [Internet]. 2017 [acesso 2018 jun 23];21:1062. Disponível em: http://www.reme.org.br/artigo/detalhes/1200.

8. Costa PCP, Garcia APRF, Toledo VP. Acolhimento e cuidado de enfermagem: um estudo fenomenológico. Texto Contexto Enferm [Internet]. 2016 jan-mar [acesso 2017 fev 20];25(1):1-7. Disponível em: http://www.scielo.br/pdf/tce/v25n1/pt_0104-0707-tce-25-014550015.pdf.

9.Fontanella BJB, Magdaleno Júnior R. Saturação teórica em pesquisas qualitativas: contribuições psicanalíticas. Psicol Estud [Internet]. 2012 jan-mar [acesso 2017 fev 20];17(1):63-71. Disponível em: http://www.scielo.br/scielo.php?pid=S1413$73722012000100008 \&$ script=sci_abstract.

10. Bardin L. Análise de conteúdo. 5 ed. Lisboa: Edições 70; 2011.

11. Penna CMM, Faria RSR, Rezende GP. Acolhimento: triagem ou estratégia para universalidade do acesso na atenção à saúde? Rev Min Enferm [Internet]. 2014 out/dez [acesso 2017 jun 20];18(4):815-22. Disponível em: http://www.reme.org.br/artigo/detalhes/965. 


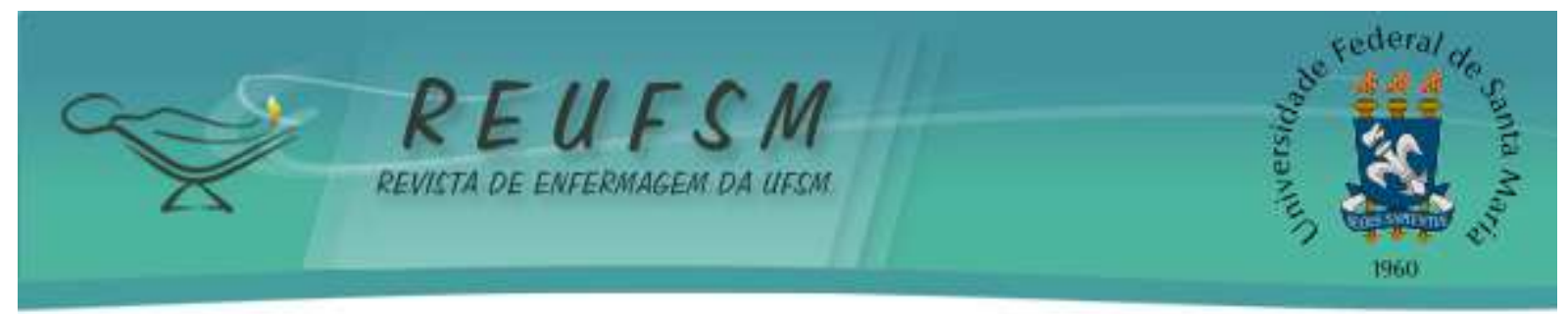

12. Schmidt SMS, Müller FM, Santos E, Ceretta PS, Garlet V, Schmitt S. Análise da satisfação dos usuários em um hospital universitário. Saúde Debate [Internet]. $2014 \mathrm{abr} / \mathrm{jun}$ [acesso 2017 jun 20];38(101):305-17. Disponivel em :http://www.scielo.br/pdf/sdeb/v38n101/0103-1104-sdeb-38-101-0305.pdf.

13. Pelisoli C, Sacco AM, Barbosa ET, Pereira CO, Cecconello AM. Acolhimento em saúde: uma revisão sistemática em periódicos brasileiros. Estudos de Psicologia I Campinas [Internet]. 2014 abr/jun [acesso 2017 jun 22];13(4):225-35. Disponível em: http://www.scielo.br/scielo.php?script=sci_arttext\&pid=S0103-166X2014000200008.

14. Roncalli AA, Oliveira DN, Silva ICM, Brito RF, Viegas SMF. Protocolo de Manchester e população usuária na classificação de risco: visão do enfermeiro. Rev Baiana Enferm [Internet]. 2017 [acesso em 2018 abr 18];31(2):e16949. Disponível em: https://portalseer.ufba.br/index.php/enfermagem/article/view/16949.

15. Silva RMCRA, Oliveira DC, Pereira ER. A produção discursiva dos profissionais acerca da humanização em saúde: singularidade, direito e ética. Rev Latinoam Enferm [Internet]. 2015 set/out [acesso 2017 jul 25];23(5):936-44. Disponível em: http://www.scielo.br/pdf/rlae/v23n5/pt_0104-1169-rlae-23-05-00936.pdf.

16. Caveião C, Hey AP, Montezeli JH, Barros APMM, Sordi JÁ, Conde Santos SC. Desafios ao enfermeiro na implantação da classificação de risco em unidade mista. REUFSM [Internet]. 2014 jan/mar [acesso 2017 out 20];4(1):189-96. Disponível em: https://periodicos.ufsm.br/reufsm/article/view/10527.

17. Ferreira JA, Araújo GC. Humanização na saúde: uma análise dos sentidos na óptica do trabalho cotidiano. Textos \& Contextos [Internet]. 2014 jan/jun [acesso 2017 jul 26];23(5):199-213. Disponível http://revistaseletronicas.pucrs.br/ojs/index.php/fass/article/view/16519.

18. Feitosa MM, Silva ICG, Costa RTS, Andrade ICF, Souza Neto VL, Silva RAR . Acolhimento com classificação de risco na unidade de pronto atendimento: um relato de experiência. REUFSM [Internet]. 2017 jan/fev [acesso 2017 set 01];7(1):136-43. Disponível em: https://periodicos.ufsm.br/reufsm/article/view/17173.

19. Baião BS, Oliveira RA, Lima VVPC, Matos MV, Alves KAP. Acolhimento humanizado em um posto de saúde urbano do distrito federal, Brasil. Rev APS [Internet]. 2014 jul/set [acesso 2017 jul 20];17(3):291-302. Disponível em: https://aps.ufjf.emnuvens.com.br/aps/article/view/1870.

20. Freitas RJM, Pereira MFA, Lima CHP, Melo JN, Oliveira KKD. A violência contra os profissionais da enfermagem no setor de acolhimento com classificação de risco. Rev Gaúcha Enferm. 2017 [acesso 2018 abr 18];38(3):e62119. Disponível em: http://seer.ufrgs.br/index.php/RevistaGauchadeEnfermagem/article/view/62119.

21. Weykamp JM, Pickersgill CS, Cecagno D, Vieira FP, Siqueira HCH. Acolhimento com classificação de risco nos serviços de urgência e emergência: aplicabilidade na enfermagem. RENE [Internet]. 2015 maio-jun [acesso 2017 jul 20];16(3):327-36. Disponível em: http://www.revistarene.ufc.br/revista/index.php/revista/article/viewFile/1962/pdf. 


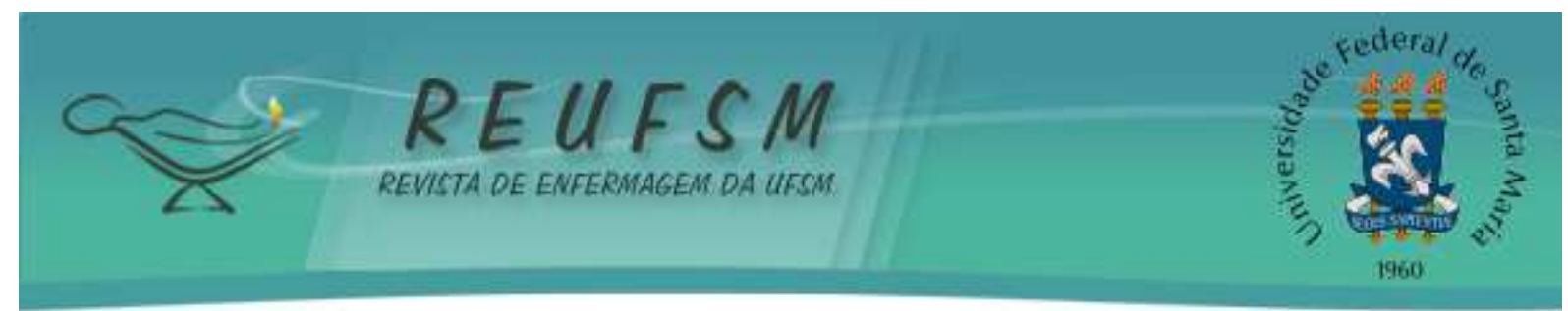

22. Hitchcock M, Gillespie B, Crilly J, Chaboyer W. Triage: an investigation of the process and potential vulnerabilities. J Adv Nurs. 2014 acesso 2018 abr 17];70(7):1532-41. Disponível em: https://onlinelibrary.wiley.com/doi/full/10.1111/jan.12304.

23. Norberg G, Sundström BW, Christensson L, Nyström M, Herlitz J. Swedish emergency medical services' identification of potential candidates for primary healthcare: retrospective patient record study. Scand J Prim Health Care [Internet]. 2015 [acesso 2018 abril 17]. Disponível em: https://www.ncbi.nlm.nih.gov/pmc/articles/PMC4750742/pdf/ipri-33-311.pdf.

24. Oliveira JLC, Gatti AP, Barreto MS, Bellucci Junior JA, Góes HLF, Matsuda LM. User embracement with risk classification: perceptions of the service users of an emergency care unit. Texto \& Contexto Enferm [Internet]. 2017 [acesso 2018 abr 15];26(1). Disponível: http://www.scielo.br/scielo.php?script=sci_arttext\&pid=S0104-07072017000100301.

25. Hermida PMV, Nascimento ERP, Echevarría-Guanilo ME, Brüggemann OM, Malfussi LBH. User embracement with risk classification in an emergency care unit: an evaluative study. Rev Esc Enferm USP [Internet]. 2018 [acesso 2018 abr 18];52:e03318. Disponível: http://www.scielo.br/pdf/reeusp/v52/en_0080-6234-reeusp-S1980-220X2017001303318.pdf.

Data de submissão: 06/11/2017

Data de aceite: 03/07/2018

Autor correspondente: Natália Mendes Malta Rodrigues Costa

E-mail: nataliamaltacosta@gmail.com

Endereço: Juarez de Paula e Silva, $n^{\circ}$ 122, Dr Hassan Jorge Mourani, Guará, São Paulo.

CEP: $14.580-000$ 